\title{
Investigation of Boron Thermal Diffusion from Atmospheric Pressure Chemical Vapor Deposited Boron Silicate Glass for N-Type Solar Cell Process Application
}

\author{
Ikuo Kurachi ${ }^{1}$ and Kentaro Yoshioka ${ }^{2}$ \\ ${ }^{1}$ D\&S Inc., Tokyo 193-0834, Japan \\ ${ }^{2}$ AMAYA Co., Ltd., Saitama 343-0822, Japan \\ Correspondence should be addressed to Ikuo Kurachi; i_kurachi@mtg.biglobe.ne.jp
}

Received 9 April 2016; Accepted 7 June 2016

Academic Editor: Prakash Basnyat

Copyright (C) 2016 I. Kurachi and K. Yoshioka. This is an open access article distributed under the Creative Commons Attribution License, which permits unrestricted use, distribution, and reproduction in any medium, provided the original work is properly cited.

An atmospheric pressure chemical vapor deposition (AP-CVD) system has been newly developed for boron silicate glass (BSG) film deposition dedicating to solar cell manufacturing. Using the system, thermal boron diffusion from the BSG film is investigated and confirmed in terms of process stability for surface property before BSG deposition and BSG thickness. No degradation in carrier lifetime is also confirmed. A boron diffusion simulator has been newly developed and demonstrated for optimization of this process. Then, the boron thermal diffusion from AP-CVD BSG is considered to be the suitable method for N-type silicon solar cell manufacturing.

\section{Introduction}

In development of advanced solar cell, improvement of efficiency and reliability with maintaining low manufacturing cost is one of crucial issues. To achieve the high efficiency and reliability, the N-type silicon solar cell is the most likely candidate although the P-type silicon solar cell is now industrial standard $[1,2]$. Indeed, the P-type silicon cell has a reliability problem which is efficiency degradation due to light illumination, which is called light induced degradation (LID) caused by formation of boron and interstitial oxygen pairs [3-5]. On the other hand, the N-type silicon cell which uses the phosphorus doped silicon wafer has no such LID and higher immunity to metallic contaminations comparing to the P-type silicon cell [6]. In order to manufacture the Ntype silicon cell, a $\mathrm{P}^{+}$diffusion layer which is usually a boron doped layer has to be formed. Thus, many boron diffusion processes have been proposed and used to fabricate the Ntype silicon solar cell. Open-tube liquid source diffusion of $\mathrm{BBr}_{3}[7,8]$ must be a common industrial standard process but the number of process steps increases because of diffusion protection film formation on the opposite side. Ion implantation is the most advanced process and has precise controllability of the dopants [9]. However, crystal defects are induced by the implantation and thermal annealing after the implantation required for recovering of the crystal defects. In addition, low throughput of the implantation is also one of the problems. On the other hand, boron thermal diffusion from a deposited boron silicate glass (BSG) film is a simple and well matured method [10-12]. Particularly, the BSG film deposition using atmospheric pressure chemical vapor deposition (AP-CVD) is a cost-effective process because of the simple machine composition. In this paper, characteristic stability for process variation of the boron thermal diffusion from the BSG film deposited by newly developed AP-CVD system has been investigated. For optimization of the process, boron diffusion simulator has been developed and demonstrated for prediction of the solar cell performance.

\section{Experimental Procedure}

Czochralski- (CZ-) grown n-type (100)-oriented silicon wafers were used as starting materials. The dopant of silicon 


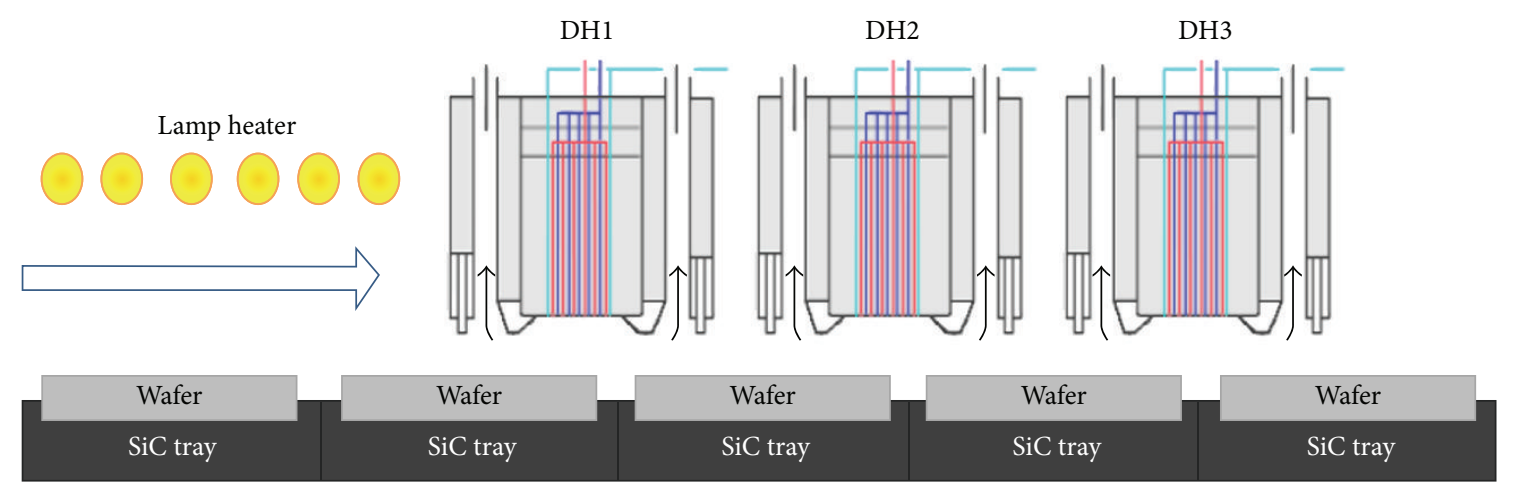

Resistive heater coils

FIGURE 1: A schematic of newly developed AP-CVD system. Deposited wafers are carried by SiC trays underneath the multideposition gas dispersion heads (DH1-3). The wafers are also heated by resistive heater coils and lamp heaters at the predeposition zone.

wafer is phosphorus with 6-9 ohm $\mathrm{cm}$ in resistivity. The wafer thickness is $675 \mu \mathrm{m}$ for the boron diffusion experiments. We compared the boron diffusion profiles between $675 \mu \mathrm{m}$ and $180 \mu \mathrm{m}$ thick wafers which are usually used in solar cell manufacturing but no difference was observed in the boron diffusion profiles. For the other experiments such as lifetime measurements, the $180 \mu \mathrm{m}$ thick wafers were used. Prior to a BSG film deposition, the wafers were cleaned by diluted hydrofluoric acid (DHF) to remove native oxide on the wafers. To study the variation of diffusion process, some wafers were dipped in $\mathrm{HCl} / \mathrm{H}_{2} \mathrm{O}_{2}$ solution after the DHF cleaning to make chemical oxide on the wafer surface. The wafers with a $5 \mathrm{~nm}$ CVD oxide film on the surface were also prepared. The BSG film was deposited by the AP-CVD system with $\mathrm{SiH}_{4} / \mathrm{O}_{2} / \mathrm{B}_{2} \mathrm{H}_{6}$ gases at $430^{\circ} \mathrm{C}$. The BSG film thickness and boron concentration were varied from 40 to $80 \mathrm{~nm}$ by controlling tray speed and $1.19 \times 10^{21}$ to $1.37 \times 10^{22} \mathrm{~cm}^{-3}$ by controlling gas flow ratio of $\mathrm{B}_{2} \mathrm{H}_{6}$ to $\mathrm{SiH}_{4}$, respectively. A $50 \mathrm{~nm}$ undoped silicate glass (USG) film was also deposited on the BSG film to prevent outdiffusion of boron during the subsequent thermal diffusion. The thermal diffusion was performed by furnace annealing in $\mathrm{N}_{2}$ ambient with varying time from 20 to $60 \mathrm{~min}$ and temperature from 900 to $1050^{\circ} \mathrm{C}$. The stand-by temperature of the furnace was $800^{\circ} \mathrm{C}$ and ramping up and down rates are 10 and $3^{\circ} \mathrm{C} / \mathrm{min}$, respectively. After the diffusion, USG and BSG films were removed using DHF solution for sheet resistance and boron depth profile measurements. To inspect the generation of boron-rich layer (BRL), wafer surface property that was hydrophobic or hydrophilic was examined during this process. The sheet resistance of diffused layer was measured by conventional four-terminal measurement. The boron depth profiles were measured by secondary ion mass spectroscopy (SIMS) using $\mathrm{O}_{2}$ as primary ions.

\section{AP-CVD BSG Deposition System}

The newly developed AP-CVD BSG deposition system consists of multigas dispersion heads (DH1, DH2, and DH3), $\mathrm{SiC}$ trays, resistive heaters, and predeposition lamp heaters as shown schematically in Figure 1 [13]. To deposit the BSG film, thermal decomposition of $\mathrm{SiH}_{4}, \mathrm{O}_{2}$, and $\mathrm{B}_{2} \mathrm{H}_{6}$ gases is used. These gases are delivered from the dispersion heads to the wafer surface. The wafers are automatically loaded and unloaded from the wafer carriers to the $\mathrm{SiC}$ trays. The wafers are heated by the resistive heaters. The resistive heaters are covered with quartz glass underneath the SiC trays. The $\mathrm{SiC}$ trays move from the wafer loading portion to the unloading portion and carry the wafers through the oxide deposition zones under the dispersion heads. The predeposition heaters prevent wafer bending especially for thin wafers. We set the important factors of system development for the solar cell manufacturing which are (i) boron concentration uniformity within a wafer and between wafers, (ii) suppression of metallic contamination, and (iii) better Cost of Ownership (CoO). Owing to the dispersion heads designed by a process simulation, good sheet resistance uniformity within $10 \%$ after the thermal diffusion is realized as shown in Figure 2. Because the wafers contact only with the trays, the $\mathrm{SiC}$ trays prevent metallic contamination during the process. Previous APCVD tools commonly use Inconel mesh belts to transfer wafers underneath the deposition head zone which means that there is possibility of metallic contaminations such as Nickel, Iron, and Chrome in the wafers. The metallic contamination in the wafers makes the problems of solar cell performance degradation. Less footprint and simple machine composition with no vacuum system is feasible for better CoO. In addition, because of the multihead concept, a stacked film such as undoped silicate glass (USG)/BSG is easily deposited by one path. The oxide is deposited only on the surface of wafers, which is suitable for the codiffusion process [14-16] and the manufacturing cost reduction. In this process, deposited BSG film thickness and boron concentration have to be controlled. The deposited film thickness can be controlled by the tray speed as well as the deposition temperature and the $\mathrm{SiH}_{4} / \mathrm{O}_{2}$ gas flow rate. The BSG boron concentration is controlled by the gas flow ratio of $\mathrm{B}_{2} \mathrm{H}_{6}$ to $\mathrm{SiH}_{4}$. The relation between the gas flow ratio and the $\mathrm{BSG}$ boron concentration which was measured by SIMS is shown in Figure 3. 


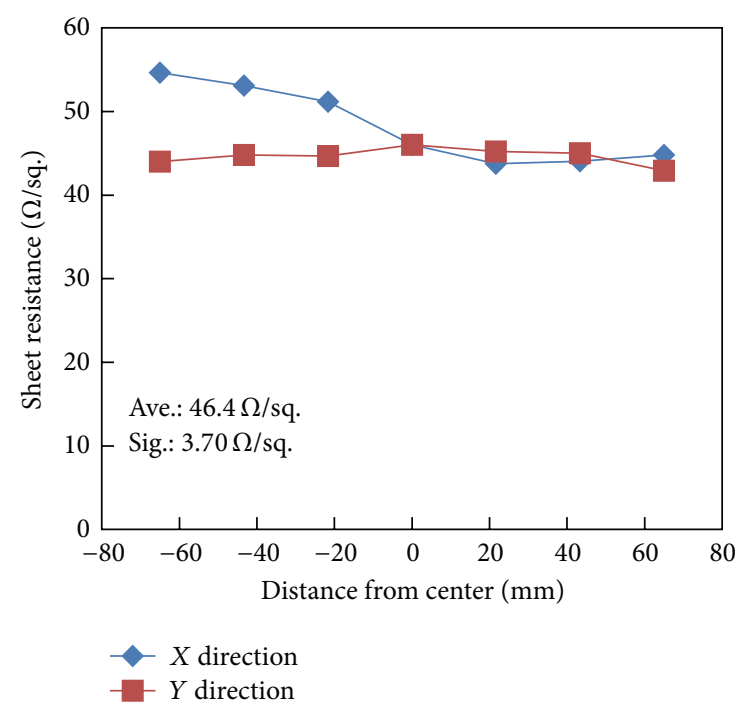

FIGURE 2: Sheet resistance uniformity within a wafer after diffusion. BSG boron concentration is $6.72 \times 10^{21} \mathrm{~cm}^{-3}$. Diffusion was performed at $950^{\circ} \mathrm{C}$ for $20 \mathrm{~min}$. The BSG film was deposited on a 156 $\times 156 \mathrm{~mm}^{2}$ pseudo square silicon wafer.

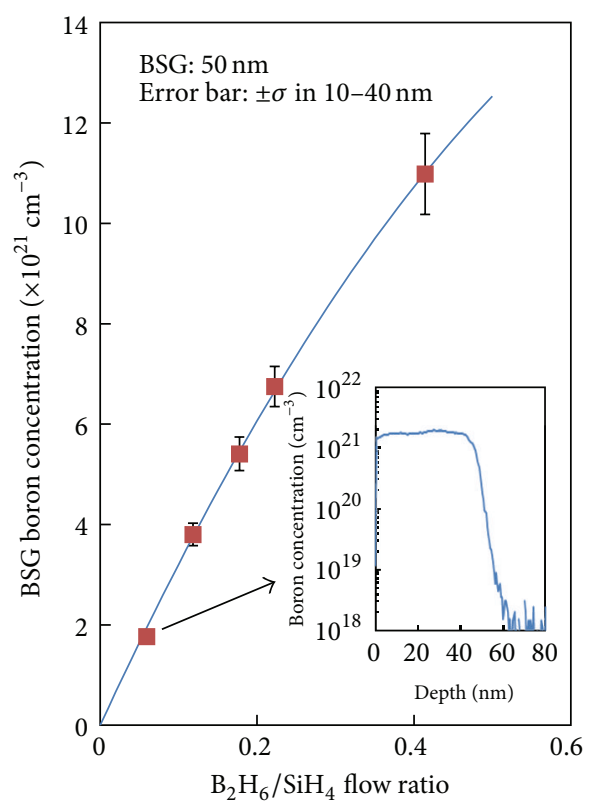

FIGURE 3: BSG boron concentration measured by SIMS as a function of flow ratio of $\mathrm{B}_{2} \mathrm{H}_{6}$ to $\mathrm{SiH}_{4}$. The inset graph shows the boron concentration profile in BSG measured by SIMS as an example. The BSG boron concentration can be varied by changing the gas flow ratio of $\mathrm{B}_{2} \mathrm{H}_{6}$ to $\mathrm{SiH}_{4}$.

\section{Results and Discussion}

4.1. Effect of Native Oxide Underneath BSG for Boron Diffusion. With consideration of the stable boron diffusion layer formation, queue time control between precleaning and BSG deposition is one of the key manufacturing parameters. When the queue time is long, the native oxide must be formed on the silicon surface. Thus, there is a possibility to alternate

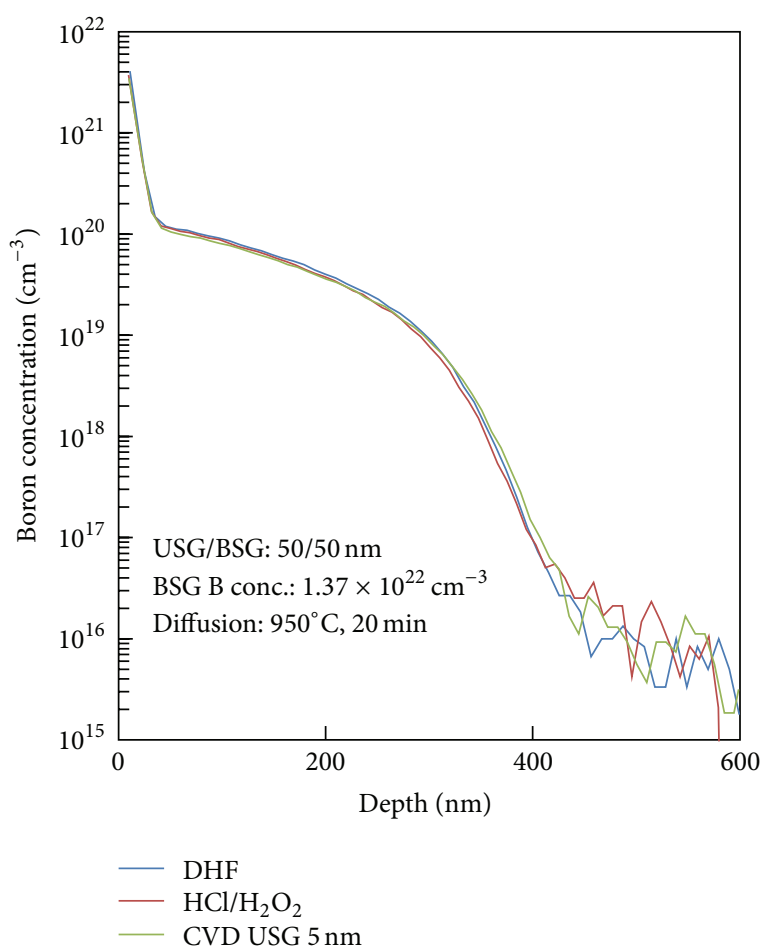

FIGURE 4: Boron profiles for the sample with DHF preclean (blue line), $\mathrm{HCl} / \mathrm{H}_{2} \mathrm{O}_{2}$ preclean (red line), and CVD USG $5 \mathrm{~nm}$ on the silicon surface (green line). In the case of HF preclean, there must be no oxide between BSG and silicon. In the case of $\mathrm{HCl} / \mathrm{H}_{2} \mathrm{O}_{2}$ preclean, around 1-2 $\mathrm{nm}$ chemical oxide exists between BSG and silicon. Even though the chemical or $5 \mathrm{~nm}$ CVD oxide exists, the profiles are identical to no oxide case.

the boron diffusion profiles due to existence of the native oxide. We have investigated the boron profiles after the thermal diffusion by SIMS when there is no oxide, chemical oxide, or CVD oxide between the BSG film and the silicon surface. The precleaning by DHF just before the BSG deposition was used to obtain the "no oxide" sample. To make chemical oxide on the surface, $\mathrm{HCl} / \mathrm{H}_{2} \mathrm{O}_{2}$ precleaning was used and the thickness of the chemical oxide was estimated to be 1$2 \mathrm{~nm}$. The sample with a $5 \mathrm{~nm}$ CVD oxide film on the surface was also prepared. After these surface treatments, a $50 \mathrm{~nm}$ BSG film was deposited. The boron diffusion profiles for these samples annealed for $20 \mathrm{~min}$ at $950^{\circ} \mathrm{C}$ are shown in Figure 4. As shown in the figure, the profiles are almost identical. It can be concluded that such chemical or CVD oxide film does not affect boron diffusion from BSG. Thus, this process has enough stability for the queue time control between the precleaning and the BSG deposition which is a superior point for the production control.

4.2. Effect of BSG Thickness for Boron Diffusion. During the thermal boron diffusion, the BSG film should work as an infinite boron diffusion source. To confirm this, $40 \mathrm{~nm}$ or $80 \mathrm{~nm}$ BSG deposited wafers were prepared and annealed for $20 \mathrm{~min}$ at $950^{\circ} \mathrm{C}$. The thickness of $40 \mathrm{~nm}$ is the thinnest for the stable BSG film deposition with consideration of incubation time 


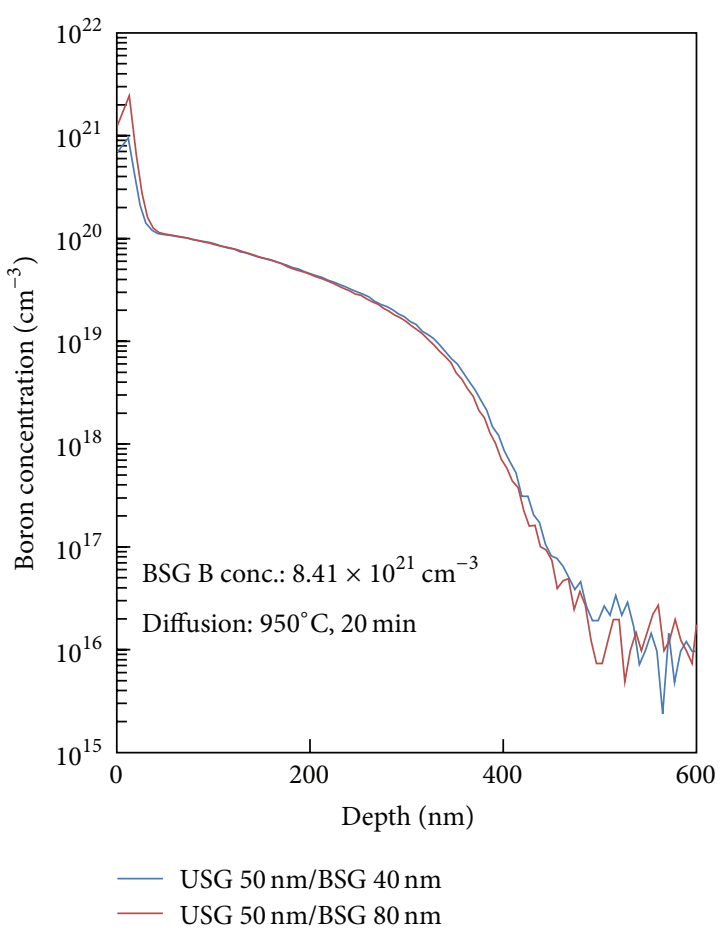

FigUre 5: Boron profiles for USG $50 \mathrm{~nm} / \mathrm{BSG} 40 \mathrm{~nm}$ (blue line) and USG $50 \mathrm{~nm} / \mathrm{BSG} 80 \mathrm{~nm}$ (red line). For both cases, the profiles are almost identical.

control. The BSG boron concentration of both samples is 8.41 $\times 10^{21} \mathrm{~cm}^{-3}$. The boron profiles after the diffusion are shown in Figure 5. There is no difference in the boron profiles. The BSG thickness of $40 \mathrm{~nm}$ is confirmed to be enough to make the infinite diffusion source of boron in this diffusion condition. Furthermore, no thickness dependence in the diffusion profile is another superior point for the production control.

4.3. BSG Boron Concentration Dependency. In this process, the $\mathrm{P}^{+}$layer sheet resistance can be controlled by changing the BSG boron concentration and/or thermal diffusion conditions such as temperature and time. Figure 6 shows the $\mathrm{P}^{+}$ sheet resistance as a function of the BSG boron concentration with the different diffusion temperatures. The diffusion time was fixed at $20 \mathrm{~min}$. As shown in this figure, the sheet resistance decreases with the BSG boron concentration up to certain BSG boron concentrations and then slightly increases. From this minimum sheet resistance point, BRL is starting to form at the surface. With the BSG boron concentration increasing, the surface boron concentration also increases. When the surface concentration reaches the solid solubility limit, BRL is formed on the surface of silicon. Because BRL consists of silicon borides, the crystal structure changes. Thus, BRL existence on the surface affects boron diffusion as described in [17]. To manipulate and predict the boron diffusion profile, a simulator to calculate the boron profile after the diffusion is indispensable because the diffusion mechanism is quite complicated $[18,19]$. Then, we have made the boron diffusion simulator by solving diffusion equation

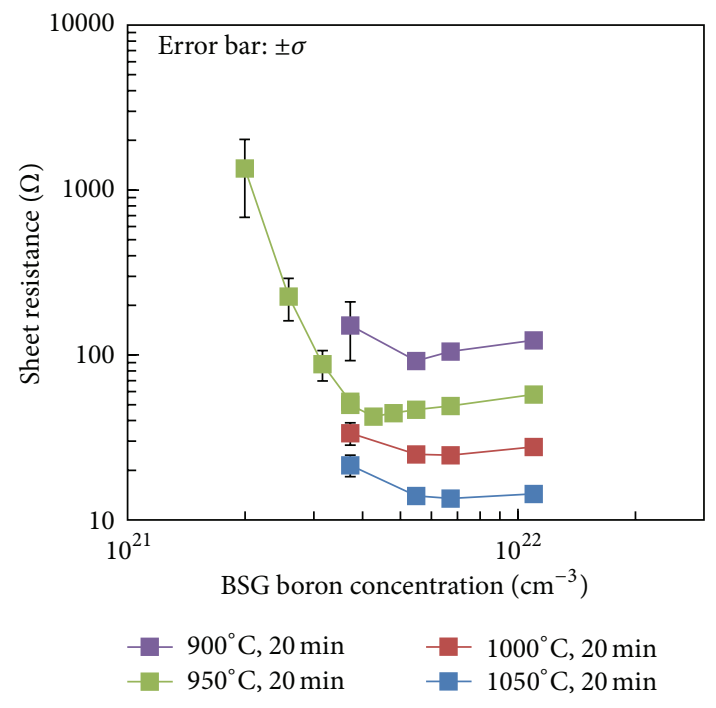

FIGURE 6: Sheet resistance dependence on BSG boron concentration as a parameter of diffusion temperatures. The sheet resistance can be controlled by the BSG boron concentration and diffusion conditions such as temperature and time. BRL is formed when the BSG concentration is higher than the concentration at the minimum sheet resistance.

numerically and the boron diffusion model of this simulation will be explained in the next section.

4.4. Carrier Lifetime after Boron Diffusion. Another important issue to apply the process to solar cell manufacturing is the effect on the carrier lifetime. It is reported that the opentube liquid source $\mathrm{BBr}_{3}$ diffusion induces the crystal defects and the carrier lifetime degradation due to the formation of BRL at the surface $[7,20]$. On the contrary, it is also reported that the formation of BRL improves the lifetime owing to metallic impurity gettering of BRL [21]. To investigate the effect on the lifetime using this process and existence of BRL on the surface, the BSG films were deposited on both sides of $156 \mathrm{~mm}$ square $180 \mu \mathrm{m}$ thick silicon wafers with two different boron concentrations, $3.72 \times 10^{21} \mathrm{~cm}^{-3}$ and $6.72 \times 10^{21} \mathrm{~cm}^{-3}$, which are without and with BRL after the diffusion, respectively. In addition, both side USG deposited Si wafers are also prepared as references. The carrier lifetimes after diffusion at different temperatures for $20 \mathrm{~min}$ are measured by microwave photoconductive decay ( $\mu$-PCD). Before the measurements, the $\mathrm{P}^{+}$diffusion layers were etched off by a mixed solution of $\mathrm{HNO}_{3}$ and HF. After RCA precleaning, the surfaces of wafers were chemically passivated by iodine to reduce the effect of surface recombination in the lifetime measurements. The lifetime was measured on area of whole wafer and averaged values were used. The results are shown in Figure 7 including the lifetime of a starting $\mathrm{Si}$ wafer without annealing. In the case of no existence of BRL on the surface $\left(3.72 \times 10^{21} \mathrm{~cm}^{-3}\right)$, the lifetimes decrease with the diffusion temperature. The lifetimes are, however, almost the same as those of the USG deposited samples. This means that the decrease of lifetimes is not due to the boron diffusion. When BRL is formed on the 


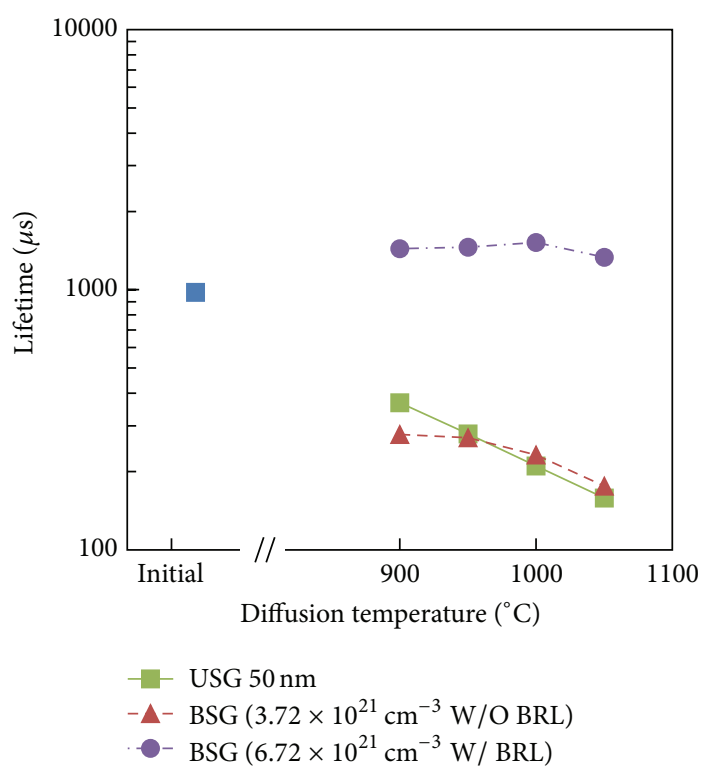

FIGURE 7: Carrier lifetimes as a function of diffusion temperature. The lifetimes of low BSG boron concentration decrease with diffusion temperature but almost the same as that of USG deposited samples. The lifetimes of samples with BRL are higher than that of the initial silicon wafer.

surface $\left(6.72 \times 10^{21} \mathrm{~cm}^{-3}\right)$, the lifetimes are more than $1 \mathrm{~ms}$ which is higher than that for the initial Si wafer. From this result, the gettering effect by BRL is confirmed in this process. It is also concluded that the thermal boron diffusion from APCVD BSG does not affect the carrier lifetime. This process was also applied to N-type silicon solar cell fabrication instead of $\mathrm{BBr}_{3}$ diffusion. We got $19.35 \%$ in efficiency using this process with comparing to $19.13 \%$ for the $\mathrm{BBr}_{3}$ diffusion. This result also supports that the boron diffusion from AP-CVD BSG does not induce any crystal defect.

\section{Boron Diffusion Profile Prediction Simulator}

The boron thermal diffusion simulator called DADiS (D\&S AMAYA Diffusion Simulator) has been newly developed to predict the diffusion profile using process parameters which are the BSG boron concentration, the thermal diffusion temperature profile including stand-by temperature, ramping up and down rate, and diffusion temperature and time. In this simulator, the diffusion equation,

$$
\frac{\partial c}{\partial t}=\frac{\partial}{\partial x}\left(D \frac{\partial c}{\partial x}\right)
$$

where $c$ is the boron concentration in silicon, $D$ is the diffusivity of boron in silicon, $x$ is the depth from the surface, and $t$ is the diffusion time, is solved numerically with the constant surface boron concentration because the BSG film is the finite boron diffusion source. The important factor

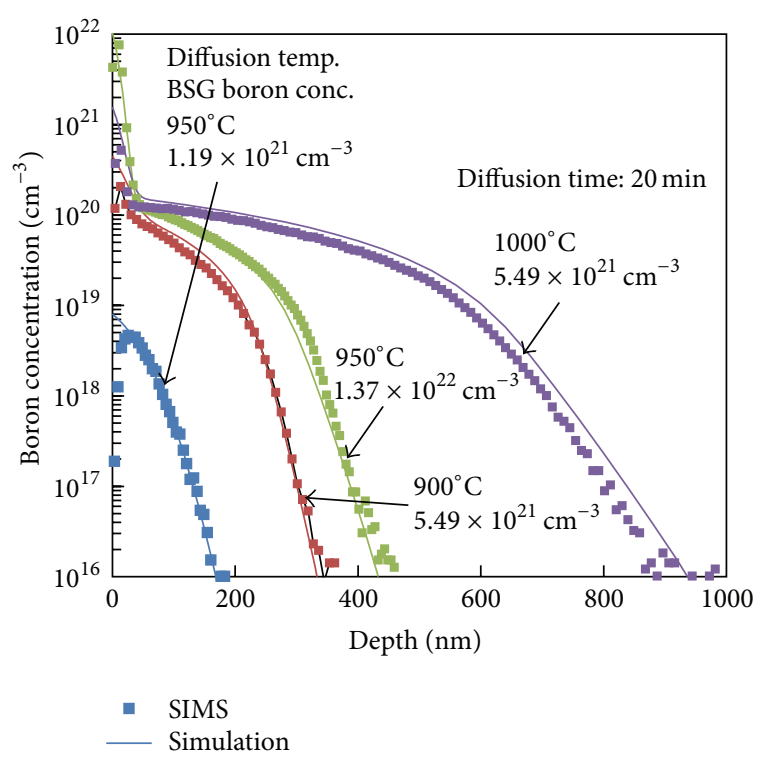

FIGURE 8: Examples of comparison between measured and simulated boron profiles after diffusion by DADiS. The simulated profiles including surface BRL area agree well with the measured profiles for wide range of the BSG boron concentrations and diffusion temperatures.

to predict the profile is the accurate diffusivity model. The diffusivity model in this simulator is used as

$$
D=D_{i} \frac{c}{2 n_{i}}\left(1+\sqrt{1+4 \frac{n_{i}^{2}}{c^{2}}}\right),
$$

where $D_{i}$ is the intrinsic diffusivity showing BSG boron concentration dependence and $n_{i}$ is the intrinsic carrier concentration at the diffusion temperature [22]. The intrinsic diffusivity has temperature dependence with the activation energy $E_{a}$ as

$$
D_{i}=D_{i_{\text {ref }}} \exp \left[\frac{-E_{a}}{k}\left(\frac{1}{T}-\frac{1}{T_{\text {ref }}}\right)\right],
$$

where $k$ is the Boltzmann constant, $T$ is the diffusion temperature, and $D_{i_{-} \text {ref }}$ is the intrinsic diffusivity at the reference temperature $T_{\text {ref }}$. To extract the diffusion activation energy, $E_{a}$, boron profiles of different diffusion temperatures are used. After the extraction of $E_{a}$, the $D_{i_{\text {_ref }}}$ dependence on BSG boron concentration is empirically modeled based on the boron profiles of different BSG boron concentration samples. The surface boron concentration equations as a function of the BSG boron concentration were also modeled. The boron profile in BRL is assumed to be a complimentary error function with fitting parameters. Detail explanation of the model is found in [23]. Examples of comparison between measured and DADiS simulated boron profiles are shown in Figure 8. Figure 9 shows the errors of DADiS in depth to measured values at given boron concentrations. The errors are almost within $15 \%$ for the ranges of 1.18 to $13.69 \times$ $10^{21} \mathrm{~cm}^{-3}$ in the BSG boron concentration, 900 to $1050^{\circ} \mathrm{C}$ in 


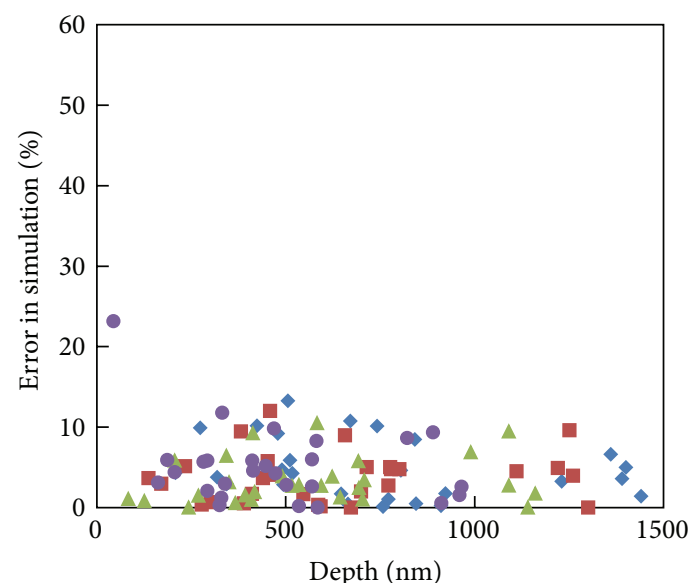

Defined at

$$
\begin{array}{ll}
1 \times 10^{16} \mathrm{~cm}^{-3} & \Delta 1 \times 10^{18} \mathrm{~cm}^{-3} \\
-1 \times 10^{17} \mathrm{~cm}^{-3} & -1 \times 10^{19} \mathrm{~cm}^{-3}
\end{array}
$$

(a)

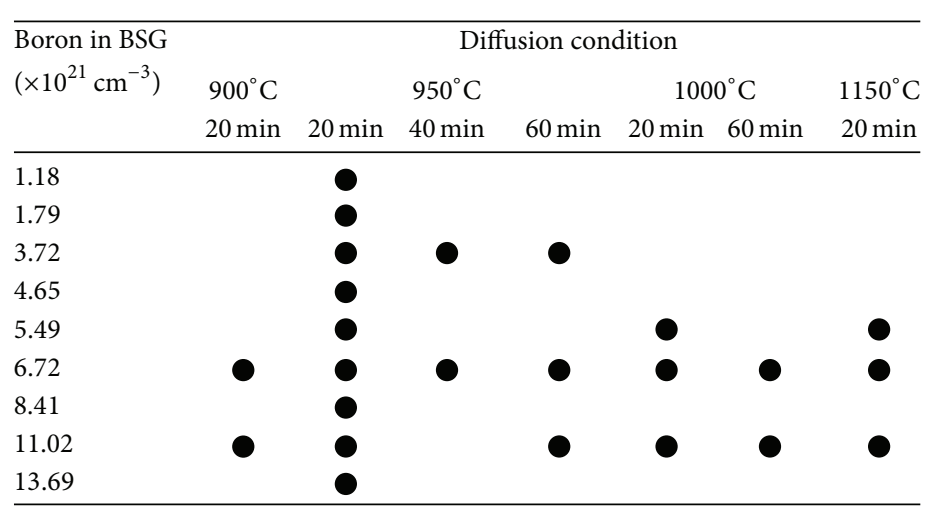

(b)

FIGURE 9: (a) Simulation error in depth at the same boron concentration. (b) is a list of examined BSG boron concentration, diffusion temperature, and time. Even though wide range of the conditions was used, the error is almost within $15 \%$. It is confirmed that the simulator DADiS is accurate and useful for the boron diffusion analysis.

the diffusion temperature, and 20 to $60 \mathrm{~min}$ in the diffusion time which are covered commonly used process conditions. Another important prediction by the simulator is the sheet resistance after the diffusion because the sheet resistance is commonly used for monitoring of the boron diffusion in the solar cell manufacturing. When the boron diffusion profile is known, the sheet resistance $R_{s}$ is given as

$$
R_{s}=\frac{1}{q \mu N_{\text {boron }}}=\frac{1}{q \mu \int_{0}^{\infty} c d x},
$$

where $q$ is the elementary electric charge, $\mu$ is the mobility of holes, and $N_{\text {boron }}$ is the number of boron atoms in the diffusion layer [24]. It is well known that the mobility has impurity concentration dependence and is empirically given as

$$
\mu=\alpha_{1}-\alpha_{2} \ln (c)
$$

where $\alpha_{1}$ and $\alpha_{2}$ are the fitting parameters [25]. Using the boron profile calculated by DADiS, (4), and (5), $R_{s}$ can be predicted when the BSG boron concentration and the diffusion conditions are known. Figure 10 shows the comparison between measured and simulated $R_{s}$ by DADiS [26]. The simulated $R_{s}$ agrees well with the measured $R_{s}$ for a wide range of 30 to $2000 \Omega /$ sq. and the error in resistance is within $20 \%$. The boron profiles and sheet resistance after the thermal diffusion are accurately predicted by DADiS with conditions of the BSG boron concentration and thermal diffusion temperature profiles. Owing to the accuracy of DADiS, the optimization of diffusion process can be achieved with less experiment [27].

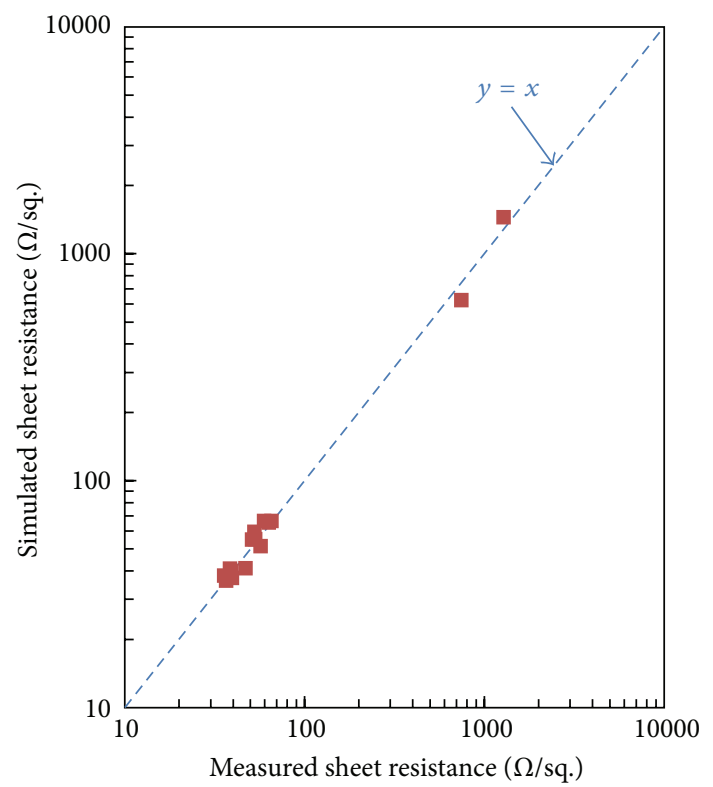

FIGURE 10: Comparison between measured and DADiS simulated sheet resistance. The error of simulation in the sheet resistance is within $20 \%$.

\section{TCAD Simulation for Prediction of Solar Cell Characteristics}

Using DADiS and well-known solar cell simulator, PC1D [28], the solar cell characteristics such as Jsc, Voc, and efficiency can be easily simulated as a function of the BSG boron concentration or diffusion conditions. The boron diffusion profiles calculated by DADiS can be used as input files of 


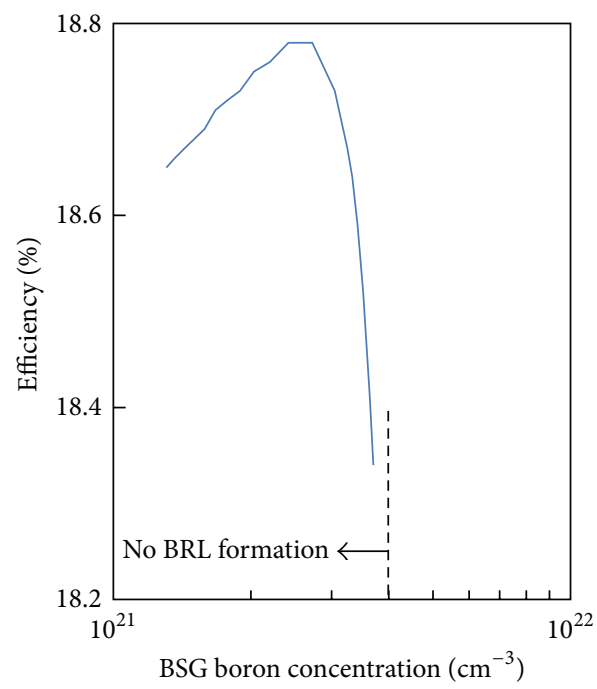

(a)

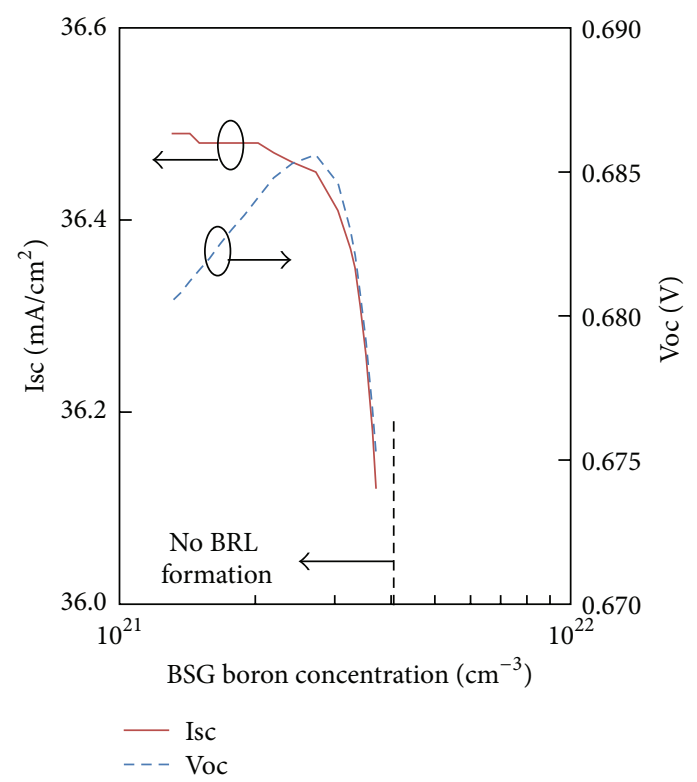

(b)

FIGURE 11: Simulated (a) efficiency, (b) short circuit current, and open circuit voltage using PC1D with DADiS as a function of BSG boron concentration. The evaluated BSG boron concentration range is lower than $4 \times 10^{21} \mathrm{~cm}^{-3}$ and no BRL is formed. The maximum point in efficiency is observed at around $3 \times 10^{21} \mathrm{~cm}^{-3}$.

PC1D to simulate the solar cell characteristics. This method, which is so called technology computer aided design (TCAD) for the solar cell, reduces the development time and cost. For example, the optimized condition of the BSG boron concentration must exist for the solar cell efficiency. The simulation results using DADiS and PC1D are shown in Figure 11. We can find out the optimized condition as shown in the figure. It is indicated that the TCAD simulation can accelerate solar cell development speed and reduce developing cost greatly.

\section{Conclusion}

The AP-CVD system to deposit the BSG films has been newly developed for boron diffusion layer formation in the $\mathrm{N}$ type silicon solar cell manufacturing. This system has good performance for manufacturing with less CoO. Using this system, the process stability of thermal boron diffusion is investigated. It is found that the boron diffusion profiles are almost identical even though there is $5 \mathrm{~nm}$ CVD oxide between the BSG film and silicon or BSG thickness is changed from $40 \mathrm{~nm}$ to $80 \mathrm{~nm}$, which indicates stable productivity by the system. The boron diffusion profiles can be manipulated by the BSG boron concentration or thermal diffusion conditions such as diffusion temperature and time. It is also confirmed that this process does not affect carrier lifetime. Because the boron diffusion mechanism is complicated, the boron diffusion profile prediction simulator, DADiS, has been developed and demonstrated for the optimization of BSG boron concentration with PC1D. It is concluded that the $\mathrm{P}^{+}$diffusion layer formation by thermal boron diffusion from AP-CVD BSG is the suitable method for the N-type silicon solar cell manufacturing.

\section{Competing Interests}

The authors declare that they have no competing interests.

\section{References}

[1] Y. Wan, C. Samundsett, T. Kho et al., "Towards industrial advanced front-junction n-type silicon solar cells," in Proceedings of the 40th IEEE Photovoltaic Specialist Conference (PVSC '14), pp. 862-865, Denver, Colo, USA, June 2014.

[2] J. Benick, B. Steinhauser, R. Muller et al., "High efficiency ntype PERT and PERL solar cells," in Proceedings of the 40th IEEE Photovoltaic Specialist Conference (PVSC '14), pp. 3637-3640, Denver, Colo, USA, June 2014.

[3] J. Schmidt, A. G. Aberle, and R. Hezel, "Investigation of carrier lifetime instabilities in CZ-grown silicon," in Proceedings of the 26th IEEE Photovoltaic Specialists Conference (PVSC '97), pp. 13-18, Anaheim, Calif, USA, October 1997.

[4] S. W. Glunz, S. Rein, J. Y. Lee, and W. Warta, "Minority carrier lifetime degradation in boron-doped Czochralski silicon," Journal of Applied Physics, vol. 90, no. 5, pp. 2397-2404, 2001.

[5] P. Basnyat, B. Sopori, S. Devayajanam et al., "Experimental study to separate surface and bulk contributions of lightinduced degradation in crystalline silicon solar cells," Emerging Materials Research, vol. 4, no. 2, pp. 239-246, 2015.

[6] D. Macdonald and L. J. Geerligs, "Recombination activity of interstitial iron and other transition metal point defects in $\mathrm{p}$ and n-type crystalline silicon," Applied Physics Letters, vol. 85, no. 18, pp. 4061-4063, 2004.

[7] M. A. Kessler, T. Ohrdes, B. Wolpensinger, R. Bock, and N.P. Harder, "Characterisation and implications of the boron rich layer resulting from open-tube liquid source BBR3 boron 
diffusion processes," in Proceedings of the 34th IEEE Photovoltaic Specialists Conference (PVSC '09), pp. 1556-1561, IEEE, Philadelphia, Pa, USA, June 2009.

[8] F. Kiefer, C. Ulzhöfer, T. Brendemühl et al., "High efficiency ntype emitter-wrap-through silicon solar cells," IEEE Journal of Photovoltaics, vol. 1, no. 1, pp. 49-53, 2011.

[9] D. L. Meier, V. Chandrasekaran, H. P. Davis et al., "N-type, ion-implanted silicon solar cells and modules," IEEE Journal of Photovoltaics, vol. 1, no. 2, pp. 123-129, 2011.

[10] K. M. Whittle and G. L. Vick, "Control of boron diffusion from a pyrolitic borosilicate glass sourc," Journal of the Electrochemical Society, vol. 116, no. 5, pp. 645-648, 1969.

[11] B. Bazer-Bachi, C. Oliver, B. Semmache et al., "Co-diffusion from boron doped oxide and POCl3," in Proceedings of the 26th European Photovoltaic Solar Energy Conference and Exhibition, pp. 1155-1159, Hamburg, Germany, 2011.

[12] K. O. Davis, Atmospheric pressure chemical vapor deposition of functional oxide materials for crystalline silicon solar cells [Ph.D. thesis], University of Central Florida, Orlando, Fla, USA, 2015.

[13] http://www.amaya-cvd.co.jp/en/prod/amax1000s.html.

[14] P. Rothhardt, T. Stoffels, R. Keding, U. Belledin, A. Wolf, and D. Biro, "Control of phosphorus doping for co-diffusion processes," in Proceedings of the 27th European Photovoltaic Solar Energy Conference and Exhibition, pp. 1917-1920, Frankfurt, Germany, 2012.

[15] P. Rothhardt, S. Meier, S. Maier, K. Jiang, A. Wolf, and D. Biro, "Characterization of POCl3-based codiffusion processes for bifacial N-type solar cells," IEEE Journal of Photovoltaics, vol. 4, no. 3, pp. 827-833, 2014.

[16] S. P. Phang and D. Macdonald, "Effect of boron codoping and phosphorus concentration on phosphorus diffusion gettering," IEEE Journal of Photovoltaics, vol. 4, no. 1, pp. 64-69, 2014.

[17] I. Kurachi and K. Yoshioka, "Analytical boron diffusivity model in silicon for thermal diffusion from boron silicate glass film," Japanese Journal of Applied Physics, vol. 54, no. 9, Article ID 096502, 2015.

[18] I. Kurachi and K. Yoshioka, "Investigation of boron solidphase diffusion from BSG film deposited by AP-CVD for solar cell application," in Proceedings of the 27th European Photovoltaic Solar Energy Conference and Exhibition, pp. 18731876, Frankfurt, Germany, 2012.

[19] I. Kurachi and K. Yoshioka, "Enhancement and retardation of thermal boron diffusion in silicon from atmospheric pressure chemical vapor deposited boron silicate glass film," Japanese Journal of Applied Physics, vol. 53, no. 3, Article ID 036504, 2014.

[20] P. J. Cousins and J. E. Cotter, "The influence of diffusioninduced dislocations on high efficiency silicon solar cells," IEEE Transactions on Electron Devices, vol. 53, no. 3, pp. 457-464, 2006.

[21] S. P. Phang, W. Liang, B. Wolpensinger, M. A. Kessler, and D. Macdonald, "Tradeoffs between impurity gettering, bulk degradation, and surface passivation of boron-rich layers on silicon solar cells," IEEE Journal of Photovoltaics, vol. 3, no. 1, pp. 261-266, 2013.

[22] M. Miyake, "Diffusion of boron into silicon from borosilicate glass using rapid thermal processing," Journal of the Electrochemical Society, vol. 138, no. 10, pp. 3031-3039, 1991.

[23] I. Kurachi and K. Yoshioka, "An accurate analytical model of boron diffusion from AP-CVD BSG for solar cell process optimization," in Proceedings of the 28th European Photovoltaic Solar Energy Conference and Exhibition, pp. 1085-1089, Paris, France, 2013.
[24] S. M. Sze, Physics of Semiconductor Devices, John Wiley \& Sons, New York, NY, USA, 2nd edition, 1981.

[25] S. C. Sun and J. D. Plummer, "Electron mobility in inversion and accumulation layers on thermally oxidized silicon surfaces," IEEE Transactions on Electron Devices, vol. 27, no. 8, pp. 1497$1508,1980$.

[26] I. Kurachi and K. Yoshioka, "Boron diffusion profile estimation using measured sheet resistance for T-CAD solar cell simulation," in Proceedings of the 29th European Photovoltaic Solar Energy Conference and Exhibition, pp. 855-858, Amsterdam, The Netherlands, 2014.

[27] A. Harada, K. Nakamura, I. Kurachi, K. Yoshioka, N. Ikeno, and A. Ogura, "Emitter layer design by thermal diffusion process for N-type crystalline silicon solar cells," in Proceedings of the 29th European Photovoltaic Solar Energy Conference and Exhibition, pp. 900-903, Amsterdam, The Netherlands, 2014.

[28] D. A. Clugston and P. A. Basore, "PC1D version 5: 32-bit solar cell modeling on personal computers," in Proceedings of the 26th IEEE Photovoltaic Specialists Conference, pp. 207-210, IEEE, Anaheim, Calif, USA, October 1997. 

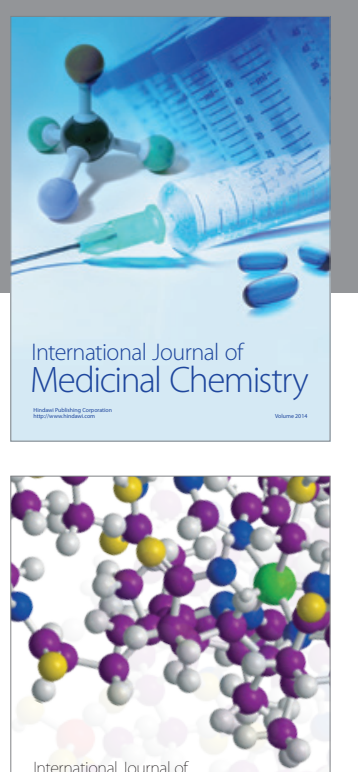

Carbohydrate Chemistry

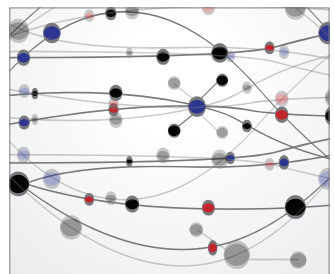

The Scientific World Journal
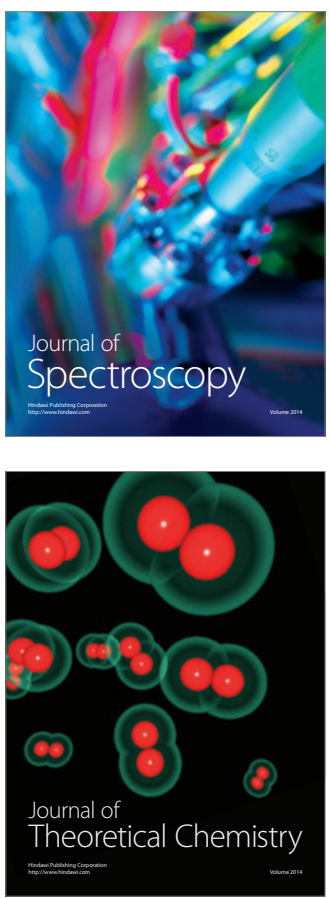
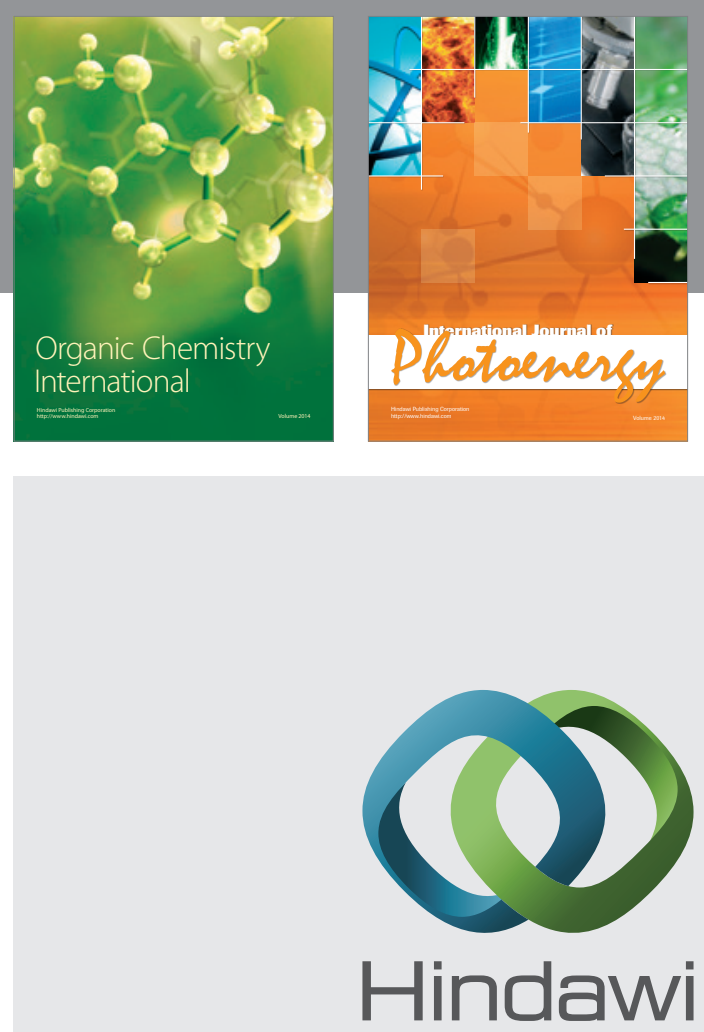

Submit your manuscripts at

http://www.hindawi.com

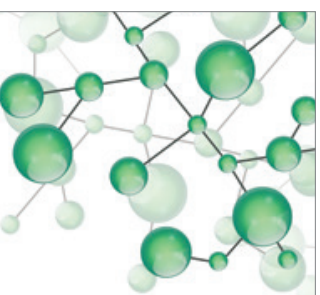

International Journal of

Inorganic Chemistry

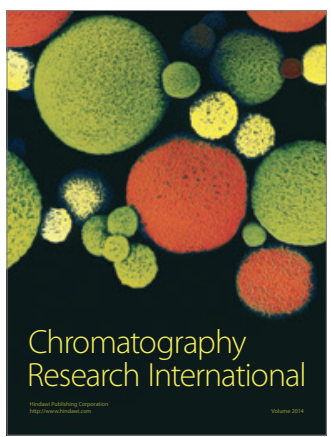

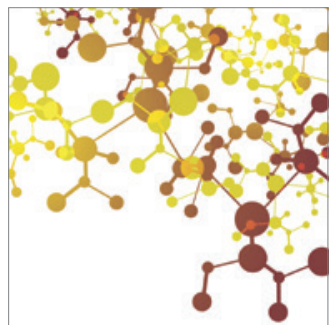

Applied Chemistry
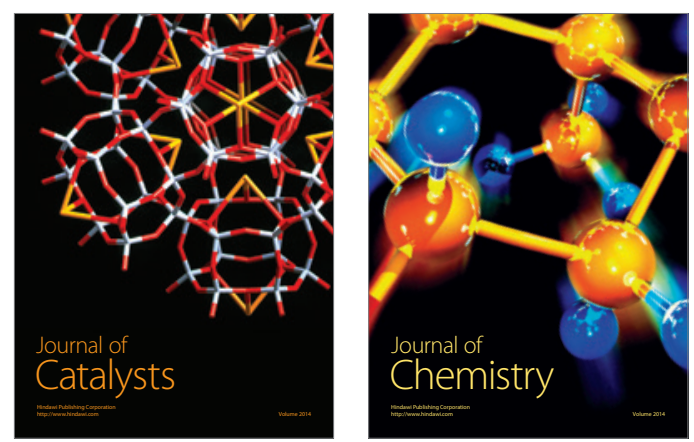
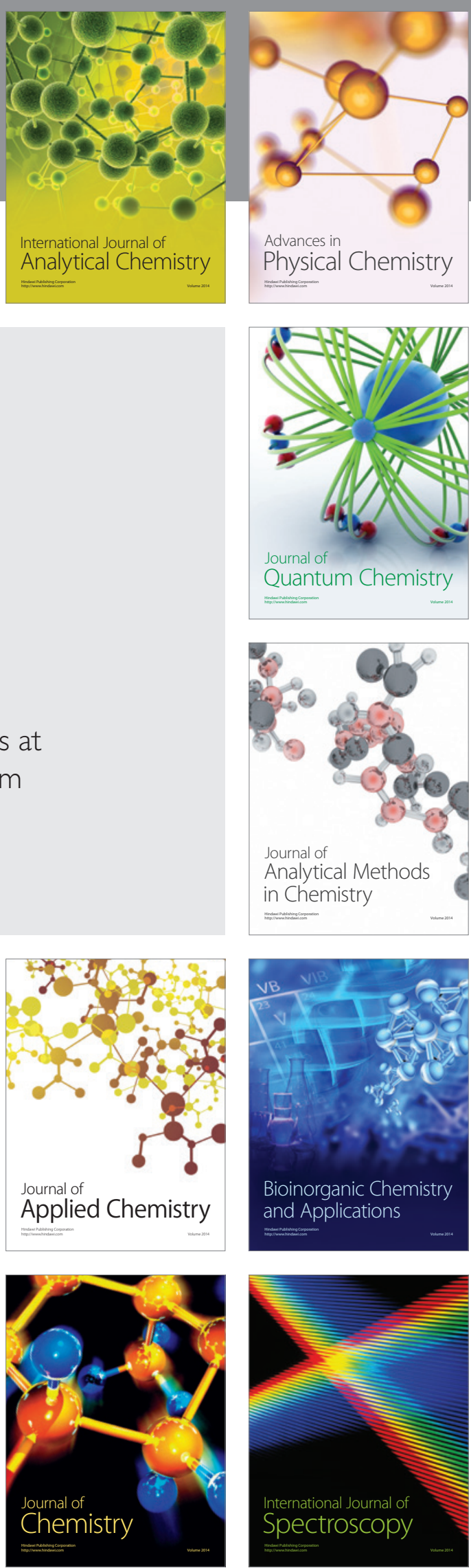